\title{
HCV core protein promotes liver fibrogenesis via up-regulation of CTGF with TGF- $\beta 1$
}

\author{
Ju Yeop Shin ${ }^{1}$, Wonhee Hur ${ }^{1}$, \\ Jin Sang Wang ${ }^{1}$, Jeong Won Jang ${ }^{1,2}$, \\ Chang Wook Kim ${ }^{1,2}$, Si Hyun Bae ${ }^{1,2}$, \\ Sung Key Jang ${ }^{3}$, Se-Hwan Yang ${ }^{3}$, \\ Young Chul Sung ${ }^{3}$, Oh-Joo Kwon ${ }^{4}$ \\ and Seung Kew Yoon ${ }^{1,2,5}$ \\ ${ }^{1}$ WHO Collaborating Center of Viral Hepatitis \\ ${ }^{2}$ Department of Internal Medicine \\ The Catholic University of Korea \\ Seoul, Korea \\ ${ }^{3}$ Division of Molecular and Life Science \\ Pohang University of Science and Technology \\ Pohang, Gyeongbuk, Korea \\ ${ }^{4}$ Department of Biochemistry \\ The Catholic University of Korea \\ Seoul, Korea \\ ${ }^{5}$ Corresponding author: Tel, 82-2-590-2622; \\ Fax, 82-2-536-9559; E-mail, yoonsk@catholic.ac.kr
}

Accepted 18 March 2005

Abbreviations: $\alpha$-SMA, $\alpha$-smooth muscle actin; BSA, bovine serum albumin; CTGF, connective tissue growth factor; ECM, extra- cellular matrix; ELISA, enzyme-linked immunosorbent assay; $\mathrm{HCV}$, hepatitis C virus; HSC, hepatic stellate cell; MMP2, matrix metalloprotease 2; PBS, phosphate-buffered saline; TBS, Trisbuffered saline; TGF- $\beta 1$, transforming growth factor $\beta 1$; TGF $\beta R I$, transforming growth factor $\beta$ receptor II; TIMP, Tissue inhibitor of metalloproteinases

\begin{abstract}
Liver cirrhosis is one of the major complications of hepatitis $C$ virus (HCV) infection, but the mechanisms underlying HCV-related fibrogenesis are still not clear. Although the roles of HCV core protein remain poorly understood, it is supposed to play an important role in the regulation of cellular growth and hepatocarcinogenesis. The aim of this study was to examine the role of HCV core protein on the hepatic fibrogenesis. We established an in vitro co-culture system with primary hepatic stellate cell (HSC) isolated from rats, and a stable HepG2-HCV core cell line which had been transfected with HCV core gene. The expressions of fibrosis-related molecules trans-
\end{abstract}

forming growth factor $\beta 1$ (TGF- $\beta 1$ ), transforming growth factor $\beta$ receptor II (TGF $\beta R$ II), $\alpha$-smooth muscle actin ( $\alpha-S M A)$ and connective tissue growth factor (CTGF) were analyzed via histological or molecular methods. In addition, the expression levels of matrix metaloprotinase-2 (MMP. 2) and collagen type I ( $\mathrm{Col}$ I) from the co-cultured media were measured by zymogram and ELISA, respectively. The expressions of $\alpha-S M A, T G F-\beta 1$, Col I, TGF $\beta R I I$ and MMP-2 were significantly increased in the co-culture of stable HepG2-HCV core with HSC. Moreover, the significant increases of CTGF and TGF- $\beta 1$ in the HCV core- expressing cells were observed by either Northern or Wes. tern blot analysis. These results suggest that HCV core protein may contribute to the hepatic fibrogenesis via up-regulation of CTGF and TGF- $\beta 1$.

Keywords: connective tissue growth factor; fibrogenesis; hepatitis $C$ virus; liver cirrhosis; stellate cell

\section{Introduction}

Hepatitis C virus (HCV) infection, one of the major public health problems worldwide, causes progressive liver disease that may end in liver cirrhosis and, eventually, in hepatocellular carcinoma. HCV is a positive-stranded RNA virus whose genome contains a single open reading frame (ORF) encoding polypeptides of 3,010-3,011 amino acids (Choo et al., 1991; Ogata et al., 1991).

Earlier studies have shown that HCV core protein regulate cellular events and induce hepatocarcinogenesis (Moriya et al., 1998; Okuda et al., 2002). We previously established a stable HepG2-core cell line which was permanently transfected with HCV core gene into HepG2 cells, and we observed that the HCV core protein play a key role in the signal transduction of apoptosis (Yang et al., 2002; Hosui et al., 2003). However, hepatic fibrogenesis relation to HCV core protein is not well understood to date due to the lack of an efficient cell culture system for HCV (Brass et al., 2002).

When the liver is injured by any cause, the liver cells including proper hepatocytes, Kuffer cells, sinusoidal endothelial cells and stellate cells secret various cytokines, hormones or oxygen free radicals, leading to hepatic damage, apoptosis or regeneration (Neuman et al., 2001). Among them, transforming growth factor $\beta 1$ (TGF- $\beta 1$ ) is known to play a key role in the fibrogenic process. Liver injury induces stellate cell activation leading to up-regulation of TGF- $\beta 1$, 
which stimulates the production and deposition of extracellular matrix (ECM), resulting in liver fibrosis (Bissell, 2001). Connective tissue growth factor (CTGF), multi-functional matricellular protein, is shown to act as an essential mediator in the hepatic fibrogenesis by stimulating ECM production (Rachfal and Brigstock, 2003). In addition, matrix metalloproteinase 2 (MMP-2), which degrades the normal subendothelial matrix, is up-regulated by activated hepatic stellate cell (HSC), which results in the destruction of collagen type IV in the basement membrane, and is then replaced with fibril collagen (Karelina et al., 2000).

Because the mechanisms of hepatic fibrogenesis by HCV have been mainly demonstrated via in vivo study (Schuppan et al., 2003), it is not clear which HCV protein directly influences the process of fibrosis. For this reason, in the present study, we investigated whether HCV core protein plays a direct role in fibrogenesis or not, using an in vitro co-culture system which is composed of a stable HepG2-core cell line and primary HSC. To more clarify the mechanism of fibrogenesis in vitro, we analyzed the expression of various proteins, growth factors and receptors including $\alpha$-smooth muscle actin $(\alpha-S M A)$, MMP-2, collagen type I (Col I), TGF- $\beta 1$, CTGF, and transforming growth factor $\beta$ receptor II (TGF $\beta$ RII) (Nelson et al., 1997; Reinehr et al., 1998; Giannelli et al., 2002; Leask et al., 2002; Qin et al., 2002).

\section{Materials and Methods}

\section{Isolation of primary HSC and cell culture}

HSC were isolated from the liver of six-week old Sprague-Dawley male rats by the collagenase perfusion two-step method described previously (Friedman, 1993). Liver isolates were centrifuged for purification by $15 \%$ nycodenz $^{(\mathrm{R})}$ (Sigma, St. Louis, MO) density gradient separation. Extracted HSC was plated on an uncoated $100-\mathrm{mm}$ culture dish and maintained with conditioned media composed of Williams' $E$ and F-12 media supplemented with $10 \%$ fetal calf serum (FCS, Invitrogen, Carlsbad), standard antibiotics, $1 \mathrm{mM}$ nonessential amino acid, $1 \mathrm{mM}$ sodium pyruvate and 0.5 $\mu \mathrm{M}$ hydrocortisone hemisuccinate (Sigma) (Ferrini et al., 1997; Castet et al., 2002). After confirming a purity level of more than $95 \%$ by endogenous vitamin A fluorescence, HSC was characterized by immunocytochemistry to analyse myofibroblasts. A HepG2 cell line purchased from ATCC (American Type Culture Collection, Manassas, VA) was cultured in DMEM (Invitrogen) supplemented with $10 \%$ fetal bovine serum (FBS, Invitrogen) at $37^{\circ} \mathrm{C}$ in a humidified chamber of $5 \% \quad \mathrm{CO}_{2}$. A stable HepG2-core cell line, such as $\mathrm{C} 18$, which contained a transfected HCV core gene in HepG2 cell line (gifted by Dr. Sung, Pohang University, Korea) was cultured in DMEM containing $200 \mu \mathrm{g} / \mathrm{ml} \mathrm{G}-418$ (Invitrogen).

\section{In vitro co-culture system of a stable HepG2-core} cell line with HSC

To elucidate the relationship between HCV core protein and hepatic fibrosis, we established two-way in vitro co-culture systems of a stable HepG2-core cell line with HSC. One is cell-to-cell contacted co-culture system composed of a mixture of two different cell lines designed for morphological analysis, and the other is cell-to-cell non-contacted co-culture system for molecular evaluation (Harimoto et al., 2002; Uyama et al., 2002). In the cell-to-cell non-contacted coculture system, a stable HepG2-core cell line was separated from HSC by a $0.2-\mu \mathrm{m}$ Anopore semipermeable membrane (Nalge Nunc. Naperville, IL). In the mixed co-culture, plating of $\mathrm{HSC}$ at $1.5 \times 10^{5}$ cells per Lab Tek II eight-chamber slide is followed by stable HepG2-core cells or HepG2 cells as a negative control at the same number of cells in different chamber slide for immunocytochemistry. Following 24 h culture in DMEM supplemented with $10 \%$ FBS, the cells were washed with phosphate buffer saline (PBS) and cultured for another $24 \mathrm{~h}$ in serum-free DMEM. After culture, the media was collected and stored at $-20^{\circ} \mathrm{C}$ until use.

\section{Enzyme linked-immunosorbent assay (ELISA)}

To quantify the expression levels of TGF- $\beta 1$ and Col I in single culture and co-culture, ELISA from culture media was performed over time. In brief, each sample from culture media was dispensed into 96-well microtiter plates (Nalge Nunc) with coating buffer (50 $\mathrm{mM}$ carbonate, $1.59 \mathrm{~g} / \mathrm{L} \mathrm{Na} \mathrm{CO}_{3}$ and $2.93 \mathrm{~g} / \mathrm{L} \mathrm{NaHCO}_{3}$, $\mathrm{pH}$ 9.6) and incubated at $4{ }^{\circ} \mathrm{C}$ overnight. The plates were then rinsed with PBS with $0.05 \%$ Tween-20 (PBST), reacted firstly with specific antibodies against TGF- $\beta 1$ and $\mathrm{Col} I$ at $37^{\circ} \mathrm{C}$ for $1 \mathrm{~h}$ and secondly with supplied horseradish peroxidase (HRP) conjugated goat anti-mouse IgG (Zymed, San Francisco; diluted at $1: 3,000)$.

After being washed three times with PBST, the plates were developed by incubation for $30 \mathrm{~min}$ at room temperature with 3,3', 5,5-tetramethyl benzidine (TMB) as the substrate. Reaction was stopped by 1 $\mathrm{M} \mathrm{H}_{2} \mathrm{SO}_{4}$ and the absorbance at $450 \mathrm{~nm}$ was determined on a microplate reader. The experiment was independently performed three times.

\section{Immunocytochemistry}

For the immunocytochemical staining, the mixed cells of HSC with stable HepG2-core or HepG2 were fixed in pre-cold methanol at $-20^{\circ} \mathrm{C}$ for $15 \mathrm{~min}$ and dried at room temperature. The fixed cells were rehydrated in PBS for $10 \mathrm{~min}$ and blocking was performed with $2 \%$ bovine serum albumin (BSA) in PBS for 1 $\mathrm{h}$ (Peehl et al., 1997). The primary monoclonal antibodies against $\alpha$-SMA (Santa Cruz, CA; diluted at $1: 1,000)$, TGF- $\beta 1$ (R\&D system, $M N$; diluted at 1 : 500 ) and CTGF (abcam, MA; diluted at 1:1,000) were applied to the cells. After incubation overnight 
at $4^{\circ} \mathrm{C}$, the cells were treated with DAKO Chemmate $^{\mathrm{TM}}$ (DAKO, Glostrup, Denmark) and 3,3'-diaminobenzidine tetrahydrochloride (DAB) as substrates following the manufacturer's specifications. Finally the cells were counterstained with Mayer's haematoxylin (Sigma).

\section{Northern blot analysis}

After total RNA extraction from cultured cells by Trizol (Invitrogen), each RNA sample of $10 \mu \mathrm{g}$ per lane was separated on $1.2 \%$ agarose-formaldehyde gels, electrotransferred onto nylon membranes, and crosslinked by UV irradiation. To detect CTGF mRNA, a CDNA probe containing the human CTGF ORF, of size $850 \mathrm{bp}$, was radiolabeled with $\left[{ }^{32} \mathrm{P}\right]$-dCTP (Amersham Pharmacia Biotech, Aylesburym, UK) by random priming and then hybridized overnight at $65^{\circ} \mathrm{C}$ in $1 \% \mathrm{BSA}, 7 \%$ sodium dodecyl sulfate (SDS), 0.5 $\mathrm{M} \mathrm{NaH} \mathrm{PO}_{4}$ and $1 \mathrm{mM}$ ethylenediaminetetraacetic acid (EDTA). The membranes were washed twice in $2 \times$ SSC, $0.1 \%$ SDS for $5 \mathrm{~min}$ at $37^{\circ} \mathrm{C}$, twice more times in $1 \mathrm{XSSC}, 0.1 \% \mathrm{SDS}$ for $30 \mathrm{~min}$ at $65^{\circ} \mathrm{C}$ and finally once more in $0.2 \times \mathrm{SSC}$ for $5 \mathrm{~min}$ at $37^{\circ} \mathrm{C}$. They were then exposed to AGFA $X$-ray blue film (AGFA Gevaert, N.V.) with intensifying screens. To assess equivalent RNA loading in each lane, the membranes were rehybridized with $\beta$-actin cDNA probe (Clontech, CA).

\section{Western blot analysis}

All of the cultivated stable HepG2-core, HepG2 and cell-to-cell non-contacted co-cultured HSC were lysated in RIPA lysis buffer $(50 \mathrm{mM}$ Tris- $\mathrm{HCl}(\mathrm{pH} 7.4)$, $1 \%$ NP-40, $0.25 \%$ sodium deoxycholate, $150 \mathrm{mM}$ $\mathrm{NaCl}, 0.1 \%$ SDS, $1 \mathrm{mM}$ EDTA, $1 \mathrm{mM}$ PMSF, $1 \mathrm{mM}$ $\mathrm{Na}_{3} \mathrm{VO}_{4}, 1 \mathrm{mM} \mathrm{NaF}$ ). Protein concentrations were measured using the Bio-Rad protein assay (Bio-Rad, Hercules, CA). After boiling for 5 min lysates were separated under $10 \%$ SDS-PAGE polyacrylamide gel. Proteins were transferred to nitrocellulose membranes which were blocked in Tris-buffered saline with Tween-20 (TTBS) containing 5\% non-fat dried milk. The membranes were incubated with specific antibodies against $\alpha$-SMA (diluted at $1: 500$ ), TGF $\beta$ RII (Santa Cruz, CA; diluted at $1: 1,000$ ), Col I (Sigma; diluted at $1: 1,000$ ) and CTGF (diluted at $1: 2,500$ ) at $4^{\circ} \mathrm{C}$ overnight. After rinsing three times in TTBS, the membranes were incubated HRP conjugated antimouse and -goat $\lg G$ antibodies (diluted at $1: 2,000$ and $1: 3,000$, respectively, Amersham Bioscience UK) at room temperature for $2 \mathrm{~h}$ and then developed using a chemiluminescence detection kit (Amersham Bioscience), according to the manufacturer's guide, and exposed to AGFA X-ray blue film (AGFA). The band density was measured using TINA image software (Raytest, Straubenhardt, Germany).

\section{Zymograpy}

The culture media from cell-to-cell non-contacted co-culture was mixed with non-denatured $5 \mathrm{X}$ sample buffer (1 M Tris-Cl pH 6.8, 1\% Bromophenol Blue, $20 \%$ SDS). Media mixture was electrophoresed in $8 \%$ polyacrylamide gel containing $1 \mathrm{mg} / \mathrm{mL}$ gelatin (Sigma) (Heussen et al., 1980), and the gel was firstly rinsed twice in distilled water with $2.5 \%$ Triton $X-100$ for 10 minutes and then secondly incubated in the activation buffer $(50 \mathrm{mM}$ Tris buffer, $\mathrm{pH} 7.4$ containing $5 \mathrm{mM}$ $\mathrm{CaCl}_{2}$ and $1 \mu \mathrm{M} \mathrm{ZnCl}$ ) at $4^{\circ} \mathrm{C}$ for $12 \mathrm{~h}$. In the gel stained with Coomassie brilliant blue R-250, MMP-2, appeared as a clear area and the band density was measured using TINA image software (Raytest).

\section{Statistical analysis}

Data are shown as mean \pm SEM. Statistical comparisons were performed with unpaired Student's $t$-test. The degree of significance of the differences was considered when $P$-value below 0.05 .

\section{Results}

\section{Up-regulation of TGF- $\beta 1$ expression in stable HepG2-core cells}

To verify the presence of HCV core protein in the stable HepG2-core cell, we performed Western blot and then confirmed the expression of $\mathrm{HCV}$ core protein with $19 \mathrm{kDa}$ molecular weight in the stable cell line (data not shown).

To investigate whether HCV core protein stimulates proinflammatory cytokine, we measured TGF- $\beta 1$ level in the supernatant between HepG2-core cells and HepG2 cells at $6,9,12$ and $24 \mathrm{~h}$ by ELISA. The level of TGF- $\beta 1$ in stable HepG2-core cells over time was significantly higher than that in HepG2 cells $(P$ $<0.05$ ), suggesting that $\mathrm{HCV}$ core protein enhances TGF- $\beta 1$ expression which promotes liver fibrogenesis (Figure 1).

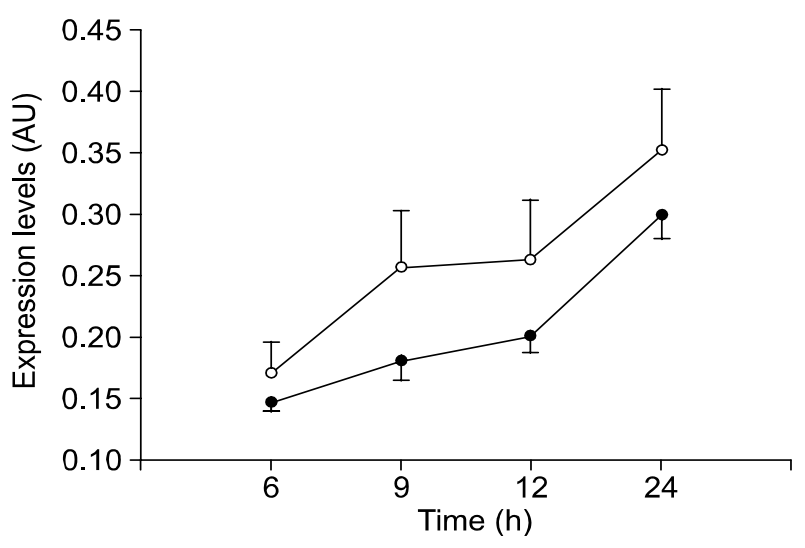

Figure 1. TGF- $\beta 1$ expression in stable HepG2 core cells $(0)$ and HepG2 cells $(\mathbf{0})$. The levels of TGF- $\beta 1$ secreted from serum free DMEM were determined at 6, 9, 12 and $24 \mathrm{~h}$ using a specific ELISA. The levels of TGF- $\beta 1$ in stable HepG2-HCV core cells over time were significantly higher than that in HepG2 cells $(P<0.05)$. Data from three independent experiments are shown as means \pm SD. 
A

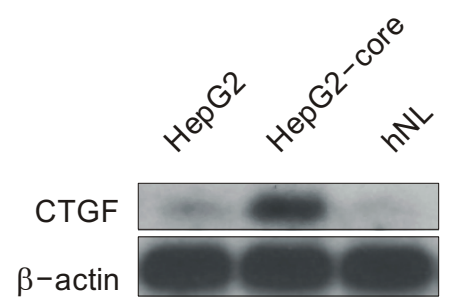

B

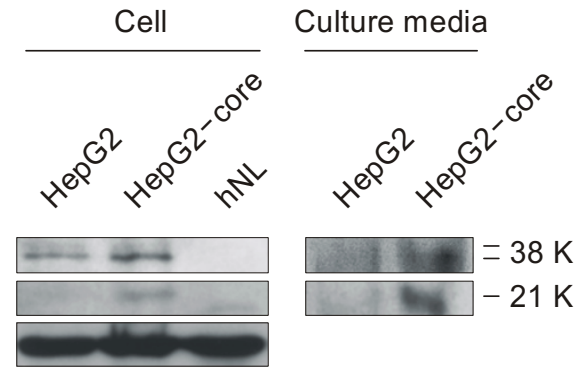

Figure 2. CTGF mRNA and protein among stable HepG2-HCV core cells, HepG2 cells and human normal liver tissue (hNL) by Northern blot and Western blot, respectively. They were cultured for $24 \mathrm{~h}$ in serum-free DMEM. (A) The expression of CTGF mRNA was significantly higher in HepG2-HCV core cells than that HepG2 cells. (B) The expressions of both the $38 \mathrm{kDa}$ doublet and $21 \mathrm{kDa}$ CTGF forms in stable HepG2-HCV core cells and HepG2 cells but not hNL. Proteolytically processed form, of $21 \mathrm{kDa}$, was shown in stable HepG2-HCV core cells and cultured media but HepG2 cells weakly.

\section{Effect of HCV core protein on CTGF expression}

A previous report suggested that CTGF is closely related in fibrogenic processes which involve proliferation, collagen synthesis and chemotaxis in mesenchymal cells (Chen et al., 2001).

We performed Northern blot analysis to evaluate the expression of CTGF mRNA in HepG2-core cells which express HCV core protein. The expression of CTGF mRNA was more pronounced in HepG2-core cells than in other HepG2 cells or normal human liver tissue as negative controls (Figure 2A). In contrast, the levels of human $\beta$-actin mRNA were similar in the three tested samples.

The CTGF protein appeared as a proteolytically processed form, of $21 \mathrm{kDa}$, in addition to the $38 \mathrm{kDa}$ doublet pattern as described in a previous report (Paradis et al., 1999). In this study, the expressions of both the $38 \mathrm{kDa}$ doublet and $21 \mathrm{kDa}$ CTGF forms were higher in stable HepG2-core cells than in HepG2 cells. Nevertheless, no target band was observed in human normal liver tissue (Figure 2B). Taken together, our results demonstrated that the levels of CTGF expression are up-regulated by HCV core protein.

Comparison of the expression levels of $\alpha-S M A$, procollagen, TGF- $\beta 1$ and TGF $\beta R \|$ in HSC co-cultured with stable HepG2-core cells and with HepG2 cells

In general, $\alpha$-SMA and desmin are known as indicating markers of activated HSC. In this study, we observed the expression of $\alpha-S M A$ and desmin through immunocytochemistry and Western blot (data not shown).

In the morphological and molecular analyses, the expressions of TGF- $\beta 1$ and CTGF were predominantly observed in HSC co-cultured with stable HepG2-core cells compared to with HepG2 cells (Figure $3 \mathrm{~A}$ ).

In addition, we quantitated the expression levels of Col I from media of HSC co-cultured with stable HepG2-core cells and HepG2 cells using ELISA. The
A

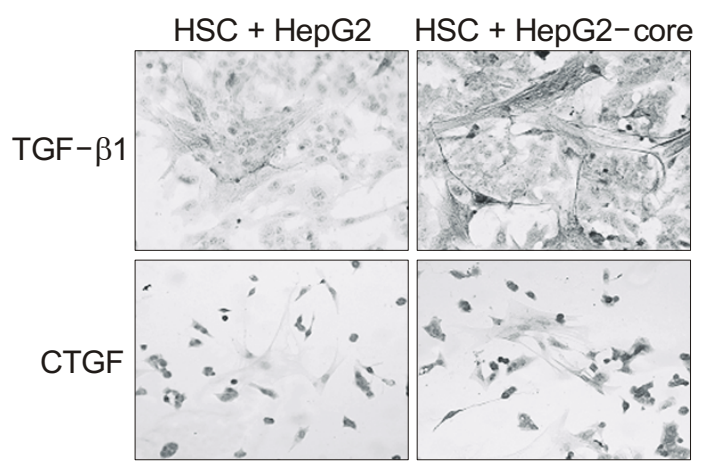

B

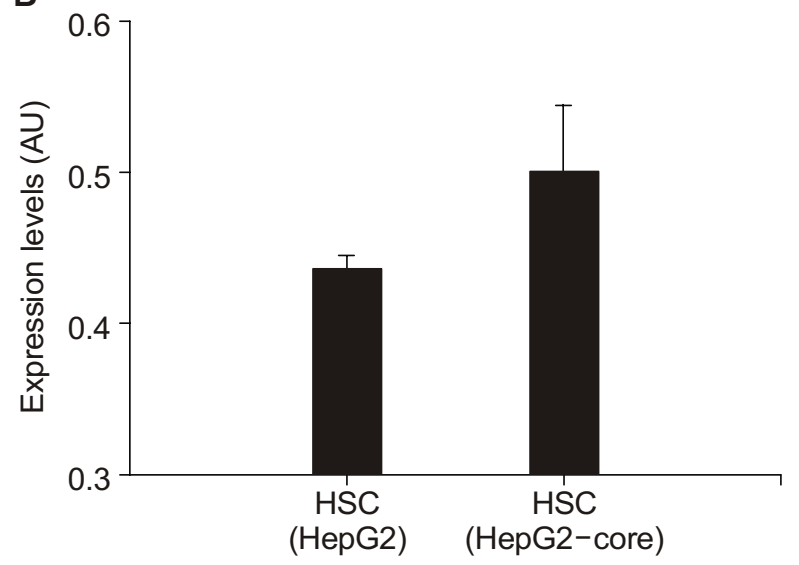

Figure 3. The expression levels of fibrosis-related proteins after HSC was co-cultured with either stable HepG2-HCV core cells or with HepG2 cells. (A) Immunocytochemical staining of TGF- $\beta 1$ and CTGF in mixed co-culture system. The characteristic HSC with long cytoplasmic process was differentiated from round hepatocytes. (B) Collagen type (Col I) expression in cell-to-cell non-contacted co-culture system. The expression level of $\mathrm{Col} I$ was determined in serum free DMEM using a specific ELISA. The expression level of Col I in stable HepG2 core was higher $27 \%$ than that of HepG2 with HSC. The level of Col I in HSC with stable HepG2-HCV core cells was significantly higher than that with HepG2 cells $(P<0.05)$. Data from three independent experiments are shown as means $\pm S D$. 


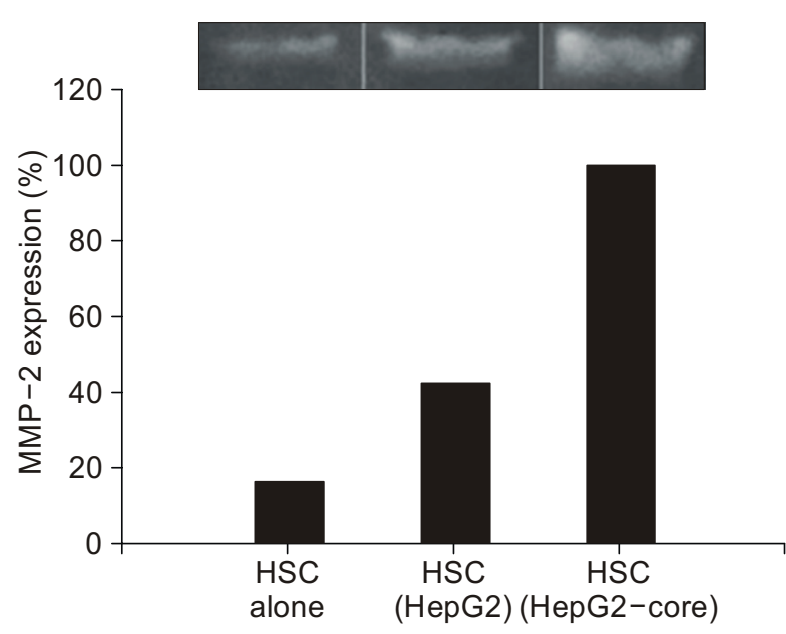

Figure 4. MMP-2 expression in HSC alone and co-cultured HSC. Each cell was cultured in serum free DMEM for $24 \mathrm{~h}$ and then the level of MMP-2 from cultured media was measured by zymogram. The expression level in HSC co-cultured with stable HepG2-core cells was 2.5 times higher than in HSC co-cultured with HepG2, and 6 times higher than in that with HSC alone

expression levels of $\mathrm{Col} \mathrm{I}$ in $\mathrm{HSC}$ co-cultured with stable HepG2-core cells were $27 \%$ higher than in those with HepG2, respectively (Figure 3B). These results suggest that $\mathrm{HCV}$ core protein enhances the fibrogenesis-related proteins leading to fibrosis and then cirrhosis in the setting of chronic liver diseases by $\mathrm{HCV}$.

As described by a previous report, MMP-2, degrades basement membrane collagen and denatures collagens by up-regulation during fibrogenic process (Friedman, 1993). In the present study, MMP-2 was quantified in culture media from HSC alone, and from HSC co-cultured with stable HepG2-core cells and with HepG2 cells by zymogram. The expression level in HSC co-cultured with stable HepG2-core cells was 2.5 times higher than in HSC co-cultured with HepG2 and 6 times higher than in that with HSC alone (Figure 4). From these results, fibrogenesis in chronic $\mathrm{HCV}$ liver diseases is stimulated and advanced by $\mathrm{HCV}$ core protein.

The previous data demonstrated that TGF $\beta R I I$ is up-regulated in addition to other fibrogenesis related proteins such as $\alpha$-SMA and procollagen during fibrogenesis (Qin et al., 2002). In this regard, we analyzed the expressions of fibrosis-related proteins such as $\alpha-S M A$, procollagen and TGF $\beta R I I$ in the separate-cultured HSC using Western blot. In our result, HSC from co-culture with stable HepG2-core cells showed higher expression of $\alpha-S M A$, procollagen and TGF $\beta R$ II than that from co-culture with HepG2 cells (Figure 5), suggesting that $\mathrm{HCV}$ core protein stimulates HSC and makes it produce $\alpha$-SMA and pro-collagen, and up-regulates TGF $\beta R I I$ which enhances TGF- $\beta 1$ expression.

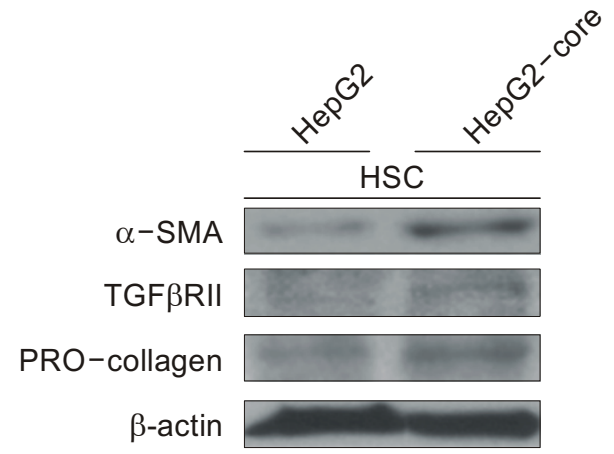

Figure 5. Western blotting for $\alpha$-SMA, procollagen and TGF $\beta R \|$ in co-cultured HSC. HSC from co-culture with stable HepG2-core cells showed higher expression of $\alpha-S M A$, procollagen and TGF $\beta R \|$ than those from co-culture with HepG2 cells, suggesting that HCV core protein up-regulated fibrogenesis-related proteins.

\section{Discussion}

Although $\mathrm{HCV}$ infection induces a high rate of chronic liver diseases including chronic hepatitis and liver cirrhosis, the mechanism of this induction has not been elucidated yet. Moreover, chronic hepatitis $C$ finally progresses into liver cirrhosis via fibrogenesis at a high rate despite anti-viral or immunomodulating therapy.

As already mentioned in numerous previous studies, HCV core protein represents multi-functional activity that plays a key role in the modulation of cell proliferation and viability, the activation of signal transduction and induction of steatosis and lipid peroxidation (Giannini and Brechot, 2003). However, the studies of HCV core-related liver fibrosis have been limited until now and they have been mainly accomplished by animal models.

The aim of this work was to investigate the role of $\mathrm{HCV}$ core protein related to hepatic fibrogenesis in vitro culture system. Recently, co-culture systems have been employed for specific purposes like research or therapeutic approach in tissue engineering (Rojkind et al., 1995; Bhatia et al., 1998). In this study, we established two different types of co-culture systems, which we named cell-to-cell contacted and non-contacted co-culture of HSC with stable HepG2core constitutively expressing $\mathrm{HCV}$ core protein. In particular, no study of the co-cultivation of HSC and hepatocyte expressing HCV core protein has been reported to date.

Hepatic fibrosis induced by variably harmful stimuli such as virus, hypoxia, chemicals, bile stasis, drugs and herbals, is characterized by abnormally excessive accumulation of ECM accompanied by exaggerated cytokine releasing. HCV core protein is thought to produce reactive oxygen species (ROS) through con- 
sequent derangement of lipid metabolism, leading to the induction of proinflammatory cytokine TGF- $\beta 1$ (Okuda et al., 2002). However, the direct mechanism by which $\mathrm{HCV}$ core protein induces fibrogenesis has not been clarified. In this study, we observed that HCV core protein significantly produced fibrosis-related proteins in an in vitro co-culture system. TGF$\beta 1$, recognized as the strongest inducers of fibrogenesis, underwent pronounced expression in media of HSC co-cultured with stable HepG2-core cells compared to that of HSC co-cultured with HepG2 cells. These results suggested that HCV core protein might regulate TGF- $\beta 1$ expression. In addition, Col I, which was produced during fibrogenesis, was increased from media of HSC co-cultured with stable HepG2-core cells, strongly suggesting HCV core protein is closely correlated to fibrogenesis.

CTGF is known to be a multifunctional matricellular protein, which has been implicated in wound healing, and several fibrotic diseases including atherosclerosis, pulmonary fibrosis, renal fibrosis and scleroderma (Igarashi et al., 1993; Igarashi et al., 1996; Oemar et al., 1997; Ito et al., 1998; Lasky et al., 1998). Although some data showed that CTGF was mainly derived from HSC during liver fibrogenesis (Paradis et al., 1999; Williams et al., 2000), it has been shown that all major cell types in the liver have the potential to produce CTGF according to initial hepatic injury and type of damage (Rachfal et al., 2003). Based on such previous results, we have immunocytochemically examined CTGF in HSC co-cultured with either stable HepG2-core cells or with HepG2 cells. In our results, CTGF was predominantly expressed in co-culture of HSC with stable HepG2-core cells than in HSC with HepG2 cells. It is interesting to note that CTGF was expressed in both HSC and HepG2-core cells. We also observed that CTGF mRNA and proteins were significantly expressed in the stable HepG2-core cells compared to in the HepG2 cells alone and in normal human liver. Furthermore, CTGF bands of both the $21 \mathrm{kDa}$ proteolytically processed form and the $38 \mathrm{kDa}$ doublet were detected in stable HepG2 core cells but not in normal human liver. However, a $38 \mathrm{kDa}$ doublet, but not the $21 \mathrm{kDa}$ form, was detected in HepG2 cells alone, suggesting that HCV core protein up-regulates CTGF in the liver with $\mathrm{HCV}$ infection.

In general, fibrogenesis is progressed by an upregulation of $E C M$ synthesis and a down-regulation of MMP activity by an increase of TIMP, a physiological inhibitor of MMP. These MMPs, TIMPs and collagens which are major components of ECM, are mainly produced in myofibroblastic cells derived from activated HSC (Knittel et al., 1999; Friedman, 2000). However, it has been reported that MMP-2, among several identified MMPs, degrades basement membrane collagen so that denatured fibril collagens replace normal collagen as ECM during fibrogenesis (Karelina et al., 2000; Schuppan et al., 2001). Our study demonstrated that MMP-2 and fibril collagen (Col I) are significantly increased in HSC co-cultured with stable HepG2-core cell compared to in HSC cocultured with HepG2 cell. This observation suggests that $\mathrm{HCV}$ core protein stimulates $\mathrm{HSC}$ to induce fibrogenesis.

During hepatic fibrogenesis, TGF- $\beta 1$ is mainly produced from myofibroblasts and its corresponding receptor (TGFRII) is activated in an autocrine fashion (Tahashi et al., 2002). In this study, TGF $\beta R I I$ expression was higher in lysates of activated HSC co-cultured with stable HepG2-core cells than in those of HSC co-cultured with HepG2 cell. Taken together with the above findings, it is evident that HCV core protein regulates TGF- $\beta 1$ and TGF $\beta R I I$ expression to direction of progressive fibrosis. The results from this co-culture system therefore support the previous findings during hepatic fibrogenesis in human and animal models (Qi Z et al., 1999).

It is not well known whether HCV directly affects $\mathrm{HSC}$ to induce liver fibrosis in chronic HCV carriers, because an efficient in vitro HCV culture system is not available and in vivo animal models such as HCV core-transgenic mice don't appear fibrosis. Therefore, our co-culture system promises to be useful for studying the dynamic signal transduction of fibrogenesis as well as for verifying new anti-fibrotic agents for liver fibrosis.

In summary, our data suggest that HCV core protein plays an important role in liver fibrogenesis by up-regulation of fibrogeneis-related proteins. Nevertheless, further studies of the role in fibrogenesis of other HCV proteins, in addition to that of HCV core protein, are required.

\section{Acknowledgement}

This study was supported by a grant from the Korean Health $21 \mathrm{R}$ \& D Project, Ministry of Health \& Welfare, Republic of Korea (02-PJ2-PG1-CH16-0002).

\section{Reference}

Bhatia SN, Balis UJ, Yarmush ML, Toner M. Microfabrication of hepatocyte/fibroblast co-cultures: role of homotypic cell interactions. Biotechnol Prog 1998;14:378-87

Bissell DM. Chronic liver injury, TGF-beta, and cancer. Exp Mol Med 2001;33:179-190

Brass V, Blum HE, Moradpour D, Of Mice and men: a small animal model of hepatitis $C$ virus replication. Hepatology 2002;35:722-4

Castet V, Fournier C, Soulier A, Brillet R, Coste J, Larrey $D$, Dhumeaux D, Maurel P, Pawlotsky JM. Alpha interferon inhibits hepatitis $C$ virus replication in primary human hepatocytes infected in vitro. J Virol 2002;76:8189-99

Chen CC, Chen N, Lau LF. The angiogenic factors Cyr61 and connective tissue growth factor induce adhesive signaling in primary human skin fibroblasts. J Biol Chem 2001; 276:10443-52

Choo QL, Richman KH, Han JH, Berger K, Lee C, Dong C, Gallegos C, Coit D, Medina-Selby R, Barr PJ. Genetic organization and diversity of the hepatitis $C$ virus. Proc Natl Acad Sci USA 1991;88:2451-5 
Ferrini JB, Pichard L, Domergue J, Maurel P. Long-term primary cultures of adult human hepatocytes. Chem Biol Interact 1997;107:31-45

Friedman S. Isolation and culture of hepatic nonparenchymal cells. In: in vitro biological systems. Volume 1. Tyson C, Frazier J, editors. Academic Press California: San Diego, 1993:292310

Friedman SL. Molecular regulation of hepatic fibrosis, an integrated cellular response to tissue injury. J Biol Chem 2000;275:2247-50

Giannelli G, Bergamini C, Marinosci F, Fransvea E, Quaranta M, Lupo L, Schiraldi O, Antonaci S. Clinical role of MMP-2/ TIMP-2 imbalance in hepatocellular carcinoma. Int $\mathrm{J}$ Cancer 2002;97:425-31

Giannini C, Brechot C. Hepatitis C virus biology. Cell Death Differ 2003;10 Suppl 1:S27-38

Harimoto $M$, Yamato $M$, Hirose $M$, Takahashi $C$, Isoi $Y$, Kikuchi A, Okano T. Novel approach for achieving doublelayered cell sheets co-culture: overlaying endothelial cell sheets onto monolayer hepatocytes utilizing temperatureresponsive culture dishes. J Biomed Mater Res 2002;62: 464-70

Heussen C, Dowdle EB. Electrophoretic analysis of plasminogen activators in polyacrylamide gels containing sodium dodecyl sulfate and copolymerized substrates. Anal Biochem 1980;102:196-202

Hosui A, Ohkawa K, Ishida $H$, Sato A, Nakanishi F, Ueda K, Takehara T, Kasahara A, Sasaki Y, Hori M, Hayashi N. Hepatitis $C$ virus core protein differently regulates the JAKSTAT signaling pathway under interleukin- 6 and interferongamma stimuli. J Biol Chem 2003;278:28562-71

Igarashi A, Okochi H, Bradham DM, Grotendorst GR. Regulation of connective tissue growth factor gene expression in human skin fibroblasts and during wound repair. Mol Biol Cell 1993;4:637-45

Igarashi A, Nashiro K, Kikuchi K, Sato S, Ihn H, Fujimoto M, Grotendorst GR, Takehara K. Connective tissue growth factor gene expression in tissue sections from localized scleroderma, keloid, and other fibrotic skin disorders. J Invest Dermatol 1996;106:729-33

Ito $\mathrm{Y}$, Aten J, Bende RJ, Oemar BS, Rabelink TJ, Weening JJ, Goldscheding R. Expression of connective tissue growth factor in human renal fibrosis. Kidney Int 1998;53:853-61

Karelina TV, Bannikov GA, Eisen AZ. Basement membrane zone remodeling during appendageal development in human fetal skin. The absence of type VII collagen is associated with gelatinase-A (MMP2) activity. J Invest Dermatol 2000; 114:371-5

Knittel T, Kobold D, Saile B, Grundmann A, Neubauer K, Piscaglia F, Ramadori G. Rat liver myofibroblasts and hepatic stellate cells: different cell populations of the fibroblast lineage with fibrogenic potential. Gastroenterology 1999;117: 1205-21

Lasky JA, Ortiz LA, Tonthat B, Hoyle GW, Corti M, Athas G, Lungarella G, Brody A, Friedman M. Connective tissue growth factor mRNA expression is upregulated in bleomycininduced lung fibrosis. Am J Physiol 1998;275:L365-L371
Leask A, Holmes A, Abraham DJ. Connective tissue growth factor: a new and important player in the pathogenesis of fibrosis. Curr Rheumatol Rep 2002;4:136-42

Moriya K, Fujie H, Shintani Y, Yotsuyanagi H, Tsutsumi T, Ishibashi K, Matsuura Y, Kimura S, Miyamura T, Koike K. The core protein of hepatitis $C$ virus induces hepatocellular carcinoma in transgenic mice. Nat Med 1998:4:1065-7

Nelson DR, Gonzalez-Peralta RP, Qian K, Xu Y, Marousis CG, Davis GL, Lau JY. Transforming growth factor-beta 1 in chronic hepatitis C. J Viral Hepat 1997;4:29-35

Neuman MG, Brenner DA, Rehermann B, Taieb J, CholletMartin S, Cohard M, Garaud JJ, Poynard T, Katz GG, Cameron RG, Shear NH, Gao B, Takamatsu M, Yamauchi M, Ohata M, Saito S, Maeyama S, Uchikoshi T, Toda G, Kumagi T, Akbar SM, Abe M, Michitaka K, Horiike N, Onji M. Mechanisms of alcoholic liver disease: cytokines. Alcohol Clin Exp Res 2001;25:251S-253S

Oemar BS, Werner A, Garnier JM, Do DD, Godoy N, Nauck M, Marz W, Rupp J, Pech M, Luscher TF. Human connective tissue growth factor is expressed in advanced atherosclerotic lesions. Circulation 1997;95:831-9

Ogata N, Alter HJ, Miller RH, Purcell RH, Nucleotide sequence and mutation rate of the $\mathrm{H}$ strain of hepatitis $\mathrm{C}$ virus. Proc Natl Acad Sci USA 1991;88:3392-6

Okuda M, Li K, Beard MR, Showalter LA, Scholle F, Lemon SM, Weinman SA. Mitochondrial injury, oxidative stress, and antioxidant gene expression are induced by hepatitis $C$ virus core protein. Gastroenterology 2002;122:366-75

Paradis V, Dargere D, Vidaud M, De Gouville AC, Huet S, Martinez V, Gauthier JM, Ba N, Sobesky R, Ratziu V, Bedossa $P$. Expression of connective tissue growth factor in experimental rat and human liver fibrosis, Hepatology 1999; 30:968-76

Peehl DM, Sellers RG. Induction of smooth muscle cell phenotype in cultured human prostatic stromal cells. Exp Cell Res 1997;232:208-15

Qi Z, Atsuchi N, Ooshima A, Takeshita A, Ueno H. Blockade of type beta transforming growth factor signaling prevents liver fibrosis and dysfunction in the rat. Proc Natl Acad Sci USA 1999;96:2345-9

Qin BY, Lam SS, Correia JJ, Lin K. Smad3 allostery links TGF-beta receptor kinase activation to transcriptional control. Genes Dev 2002;16:1950-63

Rachfal AW, Brigstock DR. Connective tissue growth factor (CTGF/CCN2) in hepatic fibrosis. Hepatol Res 2003;26:1-9

Reinehr RM, Kubitz R, Peters-Regehr T, Bode JG, Haussinger D. Activation of rat hepatic stellate cells in culture is associated with increased sensitivity to endothelin 1 . Hepatology 1998;28:1566-77

Rojkind M, Novikoff PM, Greenwel P, Rubin J, RojasValencia L, de Carvalho AC, Stockert R, Spray D, Hertzberg EL, Wolkoff AW. Characterization and functional studies on rat liver fat-storing cell line and freshly isolated hepatocyte coculture system. Am J Pathol 1995;146:1508-20

Schuppan D, Ruehl M, Somasundaram R, Hahn EG. Matrix as a modulator of hepatic fibrogenesis. Semin Liver Dis 


\section{$2001 ; 21: 351-72$}

Schuppan D, Krebs A, Bauer M, Hahn EG. Hepatitis C and liver fibrosis. Cell Death Differ 2003;10:S59-S67

Tahashi Y, Matsuzaki K, Date M, Yoshida K, Furukawa F, Sugano $\mathrm{Y}$, Matsushita M, Himeno $\mathrm{Y}$, Inagaki $\mathrm{Y}$, Inoue K. Differential regulation of TGF-beta signal in hepatic stellate cells between acute and chronic rat liver injury. Hepatology 2002;35:49-61

Uyama N, Shimahara $Y$, Kawada N, Seki S, Okuyama H, limuro Y, Yamaoka Y. Regulation of cultured rat hepatocyte proliferation by stellate cells. J Hepatol 2002;36:590-9
WHO. Hepatitis C. Fact sheet no. 164

Williams EJ, Gaca MD, Brigstock DR, Arthur MJ, Benyon RC. Increased expression of connective tissue growth factor in fibrotic human liver and in activated hepatic stellate cells. J Hepatol 2000;32:754-61

Yang SH, Lee CG, Lee CW, Choi EJ, Yoon SK, Ahn KS, Sung YC. Hepatitis $C$ virus core inhibits the Fas-mediated p38 mitogen activated kinase signaling pathway in hepatocytes. Mol Cells 2002;13:452-62 